\title{
SYNTHESIS OF Cu-CNTS NANOCOMPOSITES VIA DOUBLE PRESSING DOUBLE SINTERING METHOD
}

\author{
Marjan Darabi, Masoud Rajabi * \\ Department of Materials Science and Engineering, Faculty of \\ Technology and Engineering, Imam Khomeini International University \\ (IKIU), Qazvin, Iran
}

Received 25.08.2017

Accepted 23.12.2017

\begin{abstract}
In this research, copper $(\mathrm{Cu})$-carbon nanotubes (CNTs) nanocomposites were synthesized with different weight percentages of CNTs by double pressing double sintering (DPDS) method as well as conventional sintering method. A planetary ball mill was used to disperse CNTs in $\mathrm{Cu}$ matrix. The milled powders were first cold pressed to $450 \mathrm{MPa}$ in a uniaxial stainless-steel die with cylindrical compacts (diameter: $12 \mathrm{~mm}$ and height: $5 \mathrm{~mm}$ ). The effect of CNTs content and the DPDS method on the properties of the nanocomposites were investigated. The microstructure and phase analysis of $\mathrm{Cu}-\mathrm{CNTs}$ nanocomposite samples were studied by FESEM and X-Ray Diffraction. The electrical conductivity of nanocomposites was measured and compared to both sintering methods. Mechanical properties of $\mathrm{Cu}$-CNTs nanocomposites were characterized using bending strength and micro-hardness measurements. Enhancements of about $32 \%$ in bending strength, $31.6 \%$ in hardness and $19.5 \%$ in electrical conductivity of $\mathrm{Cu}-1 \mathrm{wt}$. \% CNTs nanocomposite synthesized by DPDS method were observed as compared to $\mathrm{Cu}-1 \mathrm{wt}$. \% CNTs nanocomposites fabricated under the similar condition by a conventional sintering process.
\end{abstract}

Keyword: Cu-CNTs nanocomposites; double pressing double sintering method; physical and mechanical properties.

\section{Introduction}

Copper is known as one the most effective materials used for thermal and electronic applications such as in large scale integrated circuits as interconnects in electronic industry [1], high-voltage switches, and magnetic confinement fusion reactors

\footnotetext{
* Corresponding author: Masoud Rajabi,m.rajabi@eng.ikiu.ac.ir, masoudrajabi@yahoo.com
} 
[2] for many years, although $\mathrm{Cu}$ usage is limited in these applications due to its low mechanical strength [3].

Since the discovery of CNTs in 1991 by Iijima [4-6], some considerable achievements are gained in different areas of research and development [7]. Also, a revolution occurred in numerous areas of materials science and technology [8]. Carbon nanotubes display excessive strength along with high thermal conductivity and exclusive electrical properties [9].

CNTs are utilized as reinforcement for a wide range of composite materials due to the spectacular mechanical, thermal, and electrical properties [10]. In this regard, the CNTs are suggested as an excellent reinforcement for enhancing mechanical efficiency of metallic components, because of their unique set of properties; extremely-high elastic modulus ( 0.5-2 TPa) [11-13], tensile strength ( 20-150 GPa) [11, 13-14], and thermal conductivity $(3000-6000 \mathrm{~W} / \mathrm{mK})[2,12,15]$, an incredible low coefficient of thermal expansion $\left(\sim 0 \times 10^{-6} 1 / \mathrm{K}\right)[12,16]$, remarkable small diameter [7], high chemical stability [7, 11], good self- lubricating properties [1], and high flexibility $[5,11,14]$. As a result, composite properties can be improved by putting CNTs into suitable matrixes, for instance, metal matrix composites [10].

However, the attention on investigations of metal matrix composites (MMCs) reinforced with CNTs has been much less than polymer matrix composites (PMCs) and ceramic matrix composites (CMCs) reinforced with CNTs. That is primarily due to problems associated with the homogenous distribution of CNTs in most metal matrixes, and poor adhesion in the interfaces between reinforcements and matrixes [17]. Recently, investigations on metal matrix composites reinforced by CNTs have increased [9]. $\mathrm{CNTs} /$ metal matrix composites have attracted great interest because of their superior mechanical properties and potential for a numerous electrical and structural purposes $[12,18]$. Many scientific studies have been carried out on the synthesis and characterization of metal matrix composites reinforced by CNTs [19].

The main requirement in the fabrication of appropriate metal matrix-CNTs nanocomposites is to achieve uniform dispersion of CNTs in the metal matrix, due to detrimental effects of agglomeration on the composite properties [3, 12]. Moreover, $\mathrm{CNTs}$ clusters usually form insufficient bonding with $\mathrm{Cu}$ particles leading to the formation of pores and cracks in the structure. Mechanical milling (MM) method has been proven as a promising technique for uniformly dispersing CNTs [3], which can be developed by enhancing milling's energy. Sintering process can be performed by conventional methods, such as vacuum hot pressing $[2,3,12,20]$, spark plasma sintering $[2,12,21]$, hot extrusion $[3,12,20]$. Also, non-sintering methods can be applied, such as electroless deposition [12, 15] and thermal spraying [12]. Powder metallurgy techniques have been developed in the last decades as a common fabrication method to produce metal matrix-CNTs composites [22-24]. One of the real advantages of this method is the fabrication of a broad range of compositions. In addition, this method prevents excessive wasting material and complicated shapes can be produced by this method with the minor need to machining. However, the most important problem with this method is the high porosity content of the sintered components that deteriorate the mechanical properties of sintered components [23, 25-26].

One of the most prevalent methods to improve mechanical properties and decrease the bulk porosity is known as double pressing double sintering [27]. The aim of this technique is to reduce porosity and increase the density of composites with the 
help of two-fold pressing [28-29]. According to previous work by German [30], an increase of about $20 \%$ in mechanical strength would result in a decline of $2-3 \%$ in porosity. The aim of this work is to compare the mechanical and physical properties of composites fabricated by DPDS technique and conventional sintering method.

\section{Experimental}

\section{Materials}

$\mathrm{Cu}$ powder with $99.9 \%$ Purity and particle size less than $25 \mu \mathrm{m}$ (produced by atomization method at Powder Metallurgy Complex of Iran - PMCI) as the matrix and multi-wall carbon nanotubes (MWCNTs) with 20-30 $\mathrm{nm}$ diameter and the average length of 10-30 $\mu \mathrm{m}$ (were provided by US Nano of America) as the reinforcement were purchased for this study. SEM and TEM images of MWCNTs are displayed in Fig. 1. As shown in Fig. 1 the CNTs have curvilinear morphology and twisted shape with nano-scale morphological features.

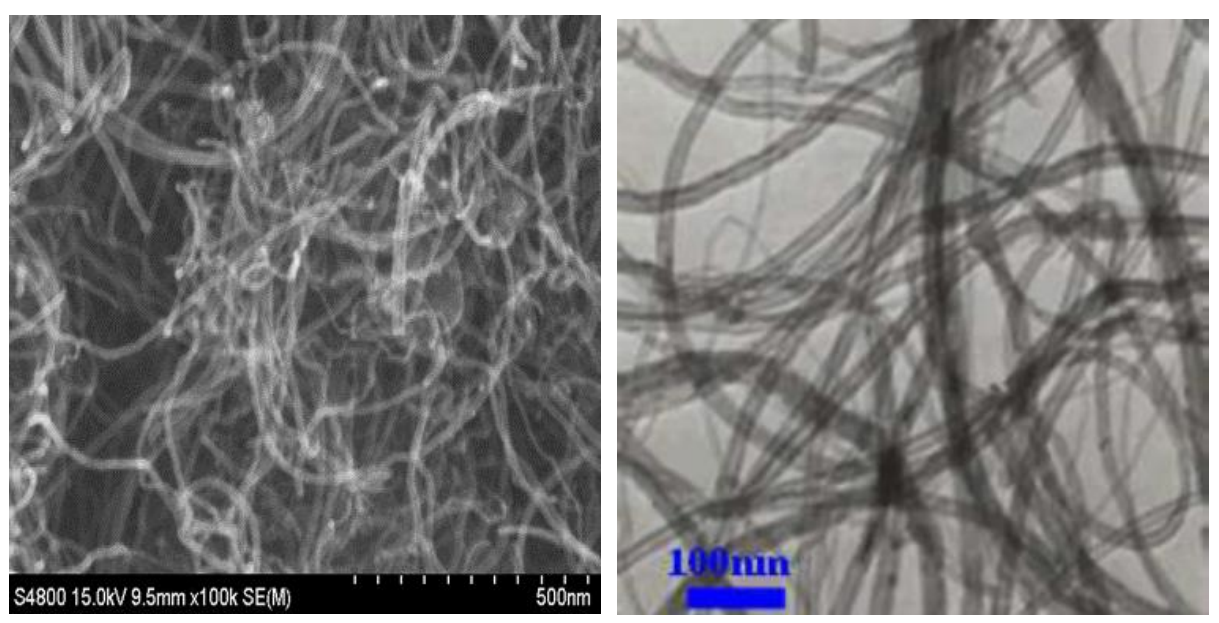

Fig. 1. Micrographs of MWCNTs, (a) SEM, and (b) TEM.

\section{Nanocomposites synthesis}

The nanocomposites were produced by powder metallurgy technique. The $\mathrm{Cu}$ powder with various amounts of CNTs $(0,0.5,1,1.5 \mathrm{wt} . \%)$ was milled at $120 \mathrm{rpm}$ in a planetary ball mill (Sanatceram Co., model: PLM2 C) within a stainless-steel jar including stainless steel milling balls of 4, 7.5, $10 \mathrm{~mm}$ diameter under argon atmosphere. Small diameter balls $(4 \mathrm{~mm})$ were applied to enhance contact areas between powders and balls. The ball to powder ratio (BPR) is 10:1 and the milling time was up to $10 \mathrm{~h}$.

The milled powders were first cold pressed under a compaction pressure of 450 $\mathrm{MPa}$ in a uniaxial stainless-steel die with cylindrical compacts (diameter: $12 \mathrm{~mm}$ and height: $5 \mathrm{~mm}$ ). The prepared compacts were pre-sintered in a tube furnace at $600{ }^{\circ} \mathrm{C}$ for $1 \mathrm{~h}$ under argon atmosphere. After cooling the specimens at room temperature, second pressing was carried out. The samples were again compacted at a pressure of $450 \mathrm{MPa}$ and finally sintered at $900{ }^{\circ} \mathrm{C}$ for $2 \mathrm{~h}$ under argon atmosphere. In order to compare, 
other samples have been fabricated by the conventional sintering method. The milled powders were put into a uniaxial die of stainless steel at $450 \mathrm{MPa}$. The compact powders were sintered in a tube furnace at $950{ }^{\circ} \mathrm{C}$ under argon atmosphere for $2 \mathrm{~h}$.

\section{Characterization}

The sintered density of the prepared samples was determined using the Archimedes principal according to ASTM B311. LECO combustion analysis has been employed to detect a low level of oxygen using an elemental combustion system (Costech4010 model). Vickers micro-hardness of the Cu-CNTs nanocomposite samples was measured using a micro-hardness tester (HVS-1000A model), with a $50 \mathrm{~g}$ loading and dwell time of $10 \mathrm{~s}$ according to ASTM E92. Also, the bending strength test was carried out using a Zwick Roaell-Z100 universal testing machine with an initial strain of $0.5 \mathrm{~mm} / \mathrm{min}$ at room temperature (according to ASTM D790). The electrical conductivity of the sintered samples was measured according to the international annealing copper standard (IACS \%) by a Sigmore 100 testing machine.

Metallography of samples was prepared using $\mathrm{SiC}$ papers of grade numbers 320 mesh to 5000 mesh. For the purpose of investigating the microstructure of samples by FESEM, samples were polished using 0.5-micron alumina suspension, felt and diamond paste $(<0.25 \mu \mathrm{m})$. In addition, samples were etched by a solution of $\mathrm{CrO}_{3}+\mathrm{HNO}_{3}+\mathrm{H}_{2} \mathrm{SO}_{4}+\mathrm{H}_{2} \mathrm{O}$. The microstructure of the obtained nanocomposite samples was investigated using field emission scanning electron microscope (FESEM) fitted with energy-dispersive X-ray spectroscopy (EDX). The grain size of the nanocomposite samples was measured by image analysis of the FESEM micrographs (Image $\mathrm{J}$ Program). Finally, XRD analysis was carried out by XPert (Philips PW 3710) diffractometer (Co $\mathrm{K}_{\mathrm{a}}$ radiation with $\left.\lambda=1.54 \mathrm{~A}^{\circ}\right)$ with voltage and the current setting of $40 \mathrm{kV}$ and $30 \mathrm{~mA}$, respectively.

\section{Results and discussion}

\section{Microstructure}

The $\mathrm{Cu}$ powder with different amounts of CNTs was milled for $10 \mathrm{~h}$. Fig. 2 indicates the FESEM micrographs of the mixed powders of $\mathrm{Cu}$-CNTs nanocomposites containing $0.5,1$ and 1.5 wt.\% CNTs. As these micrographs indicate, $\mathrm{Cu}-0.5$ wt.\% CNTs nanocomposites powder include coarse grains which were obtained due to impact, fracture and welding of $\mathrm{Cu}$ powders excessively since low amount of CNT particles may increase the contact area of $\mathrm{Cu}$ powders in the mixture. By adding $1 \mathrm{wt} . \%$ CNT, layered microstructure has been gained, however, $\mathrm{Cu}-1.5$ wt.\% CNTs nanocomposites powder agglomerates due to the high amount of CNT. 


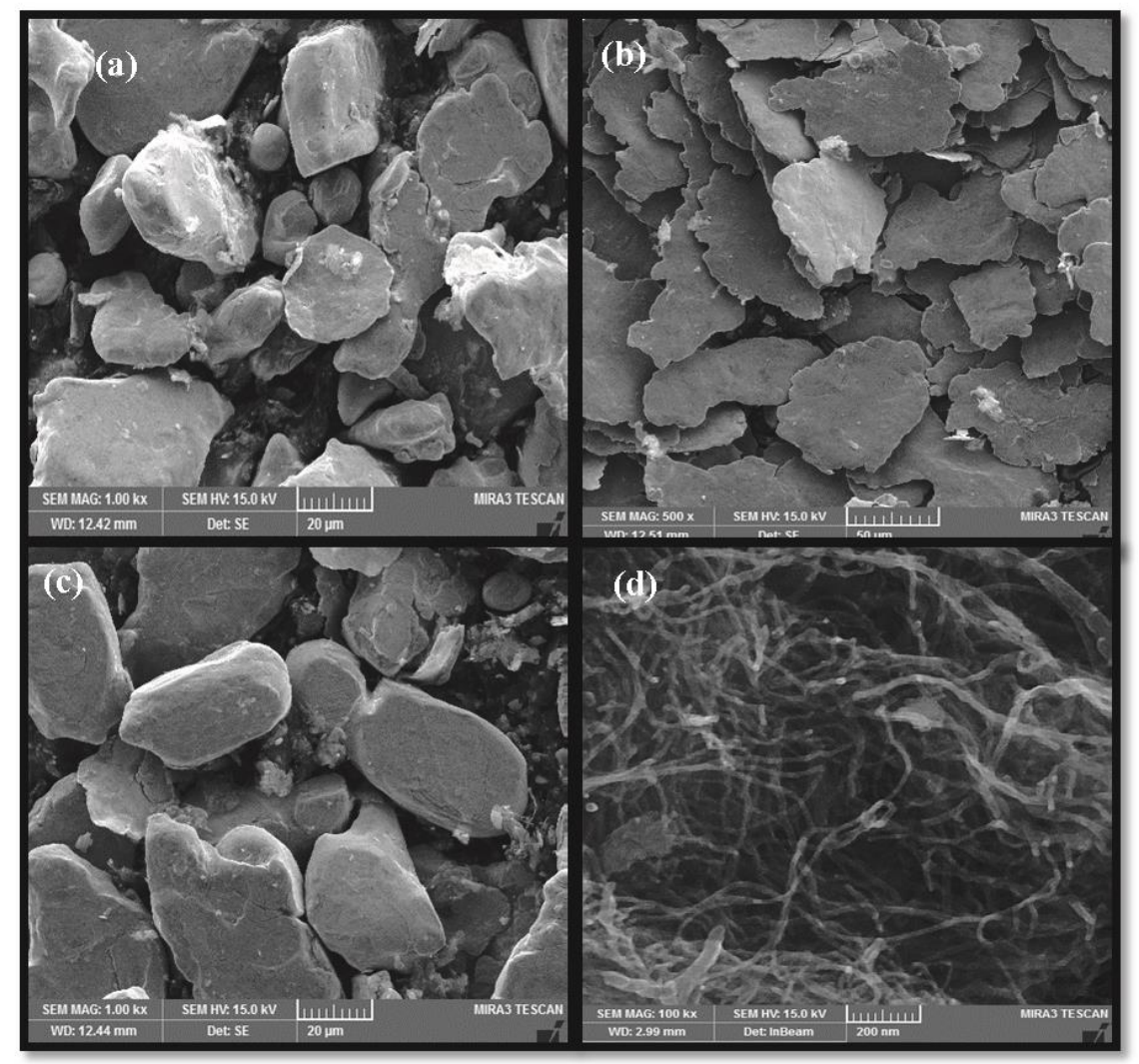

Fig. 2. FESEM micrographs of a) Cu-0.5 wt.\% CNTs, b) Cu-1wt. \% CNTs nanocomposite powders and $c, d$ ) $\mathrm{Cu}-1.5 \mathrm{wt}$.\% CNTs nanocomposite powders and agglomerated CNTs region.

$\mathrm{Cu}-\mathrm{CNTs}$ nanocomposite samples were fabricated by powder metallurgy method as well as DPDS method. Fig. 3 shows the microstructures of the etched $\mathrm{Cu}-\mathrm{CNT}$ nanocomposites containing $0.5,1$ and $1.5 \mathrm{wt} . \%$ CNTs as produced by the DPDS method.

According to Fig. 3 (a), microstructure of $\mathrm{Cu}-0.5$ wt.\% CNTs nanocomposite fabricated by DPDS shows dense structure. The Fig. 3 (b, d) indicates, the CNTs are located at the prior particle boundaries (existence of CNTs in the microstructure has been proved by an EDX analysis). Hence, the movement of dislocations in the matrix will be stopped by these CNTs, effectively. Fig. 3 (f) shows agglomeration of CNTs in the $\mathrm{Cu}-1.5$ wt.\% CNTs nanocomposite. The agglomeration of CNTs is one of the biggest challenges for CNTs reinforced composites since it leads to premature crack initiation and fracture. In fact, by increasing the number of CNTs in the copper matrix leads to agglomeration. In addition, some pores in $\mathrm{Cu}-1.5 \mathrm{wt}$ \% $\mathrm{CNT}$ s nanocomposites were produced as a result of CNTs agglomeration. It can be observed that the blank pores were increased with increasing the number of CNTs in the $\mathrm{Cu}$ matrix nanocomposites. 

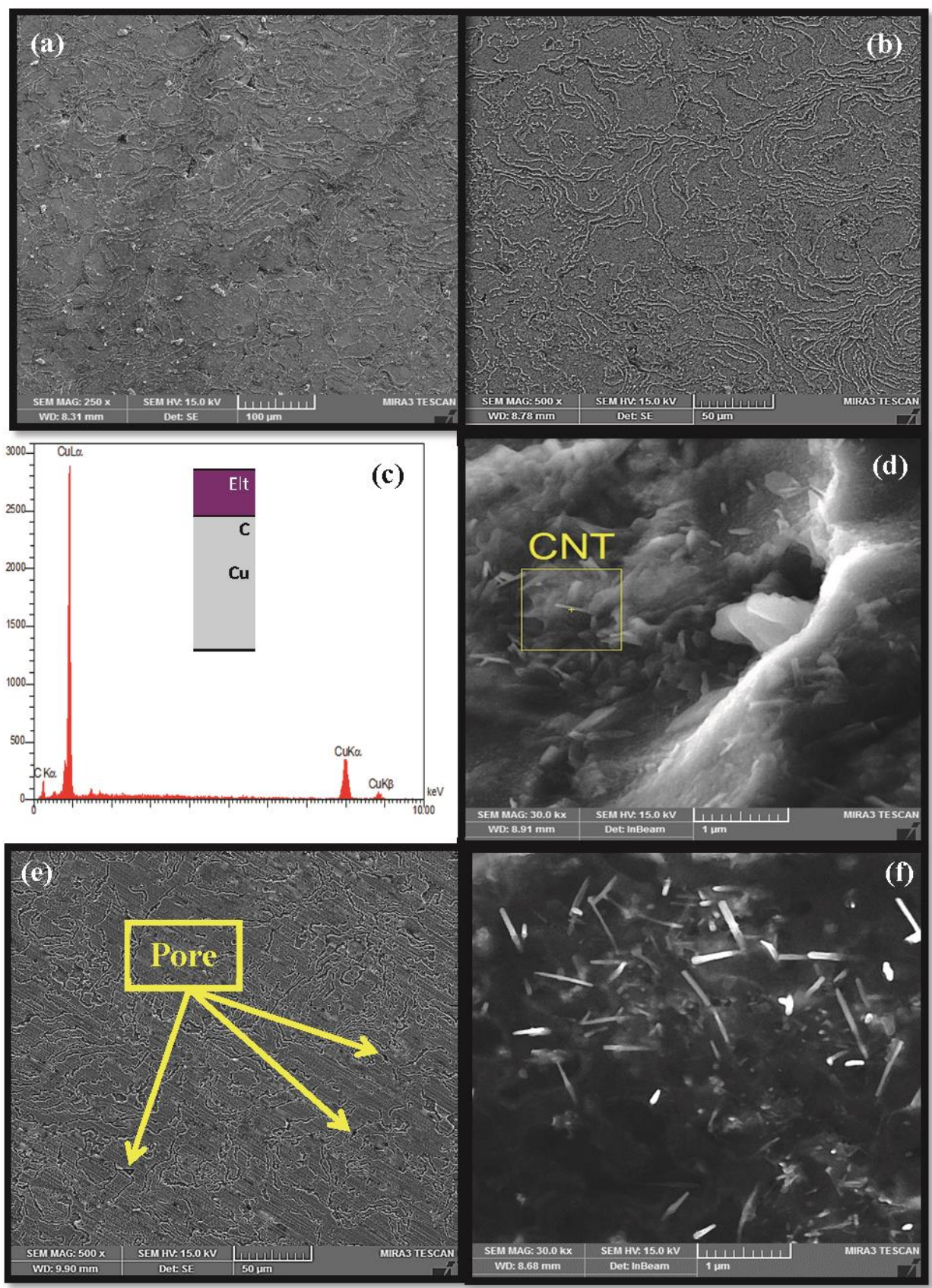

Fig. 3. FESEM micrographs of a) Cu-0.5 wt.\% CNTs nanocomposite, $(b, c, d) C u-1$ wt.\% CNTs nanocomposite and its EDX analysis and (e, f) Cu-1.5 wt.\% CNTs nanocomposite produced by DPDS method. 
Fig. 4 (a, b) shows the microstructure of $\mathrm{Cu}-0.5$ wt.\% CNTs and $\mathrm{Cu}-1$ wt.\% CNTs nanocomposite fabricated by the conventional sintering method. Distribution of CNTs in a nanocomposite with $1 \mathrm{wt} \%$ of CNTs as well as FESEM micrograph of Cu1.5 wt.\% CNTs nanocomposite are shown in Fig. 4 (c) and Fig. 4 (d) respectively. In Fig 4 , some pores in microstructure can be seen clearly which could be related to the method of sintering.

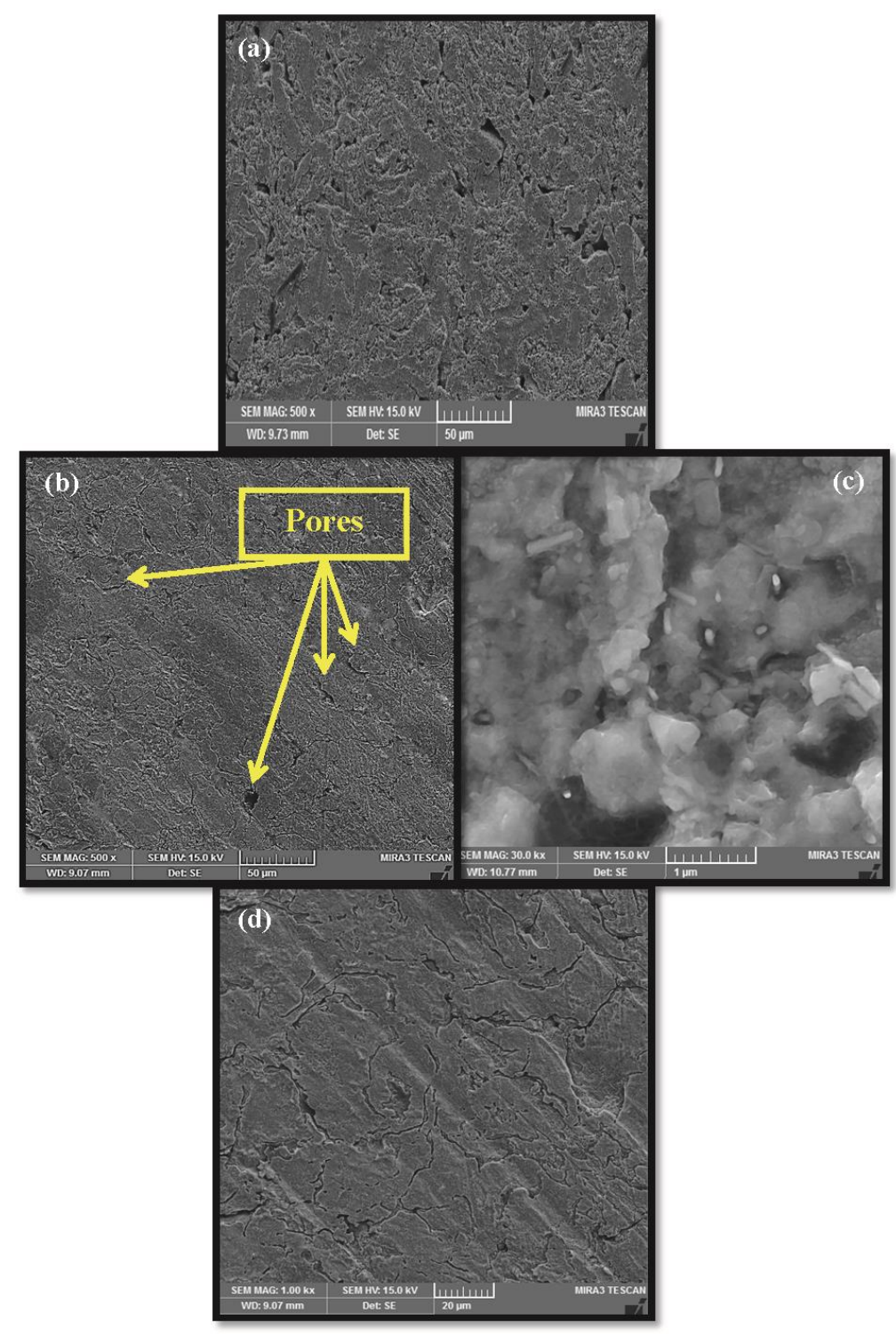

Fig. 4. FE-SEM micrographs of a) Cu-0.5 wt.\% CNTs nanocomposite, $b$, c) $C u-1$ wt.\% CNTs nanocomposite and d) $\mathrm{Cu}-1.5 \mathrm{wt} . \% \mathrm{CNTs}$ nanocomposite fabricated by the conventional sintering method. 
Taking some significant differences between nanocomposite produced by both methods into account, fewer pores are found in the microstructure of the sample produced by DPDS method that could be attributed to the mechanism of this method. The effective factors in this method include pre-sintering which acts as an annealing process and provides the possibility to apply the second step of pressing and the major effect of second pressing on microstructure which causes a dense microstructure with less porosity. In terms of grain size, the finer microstructure is demonstrated for the nanocomposite produced by DPDS method. The average grain size of the nanocomposites produced by DPDS is significantly smaller (Fig. 5) which could be due to impressive effect of first-step compacting and sintering resulting in the limit of space for grain growth in second-step sintering. $\mathrm{Cu}-\mathrm{CNT}$ composites have been finer by adding CNT particles; in particular $\mathrm{Cu}-1$ wt.\% CNTs nanocomposite produced by DPDS method, as its fine microstructure has been shown in Fig. 3 (b), although by adding more CNTs to composites (Cu-1.5 wt.\% CNTs), agglomeration of CNTs prevents from a uniform distribution of them among $\mathrm{Cu}$ particles and also fine microstructure. Thus, values of grain size for $\mathrm{Cu}-1.5$ wt.\% CNTs nanocomposites increase.

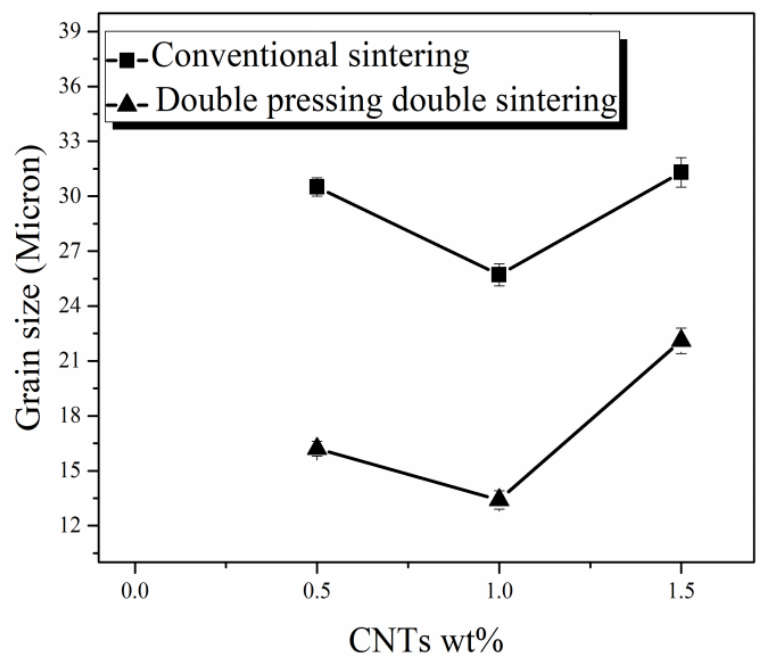

Fig. 5. Values of grain size of Cu-CNT nanocomposites as a function of CNTs wt.\%.

$X$-ray analysis

The x-ray diffraction patterns of $\mathrm{Cu}-1 \mathrm{wt}$. \% CNTs and $\mathrm{Cu}-1.5 \mathrm{wt}$. \% CNTs nanocomposites produced by conventional sintering and DPDS methods are shown in Fig. 6. Also, a pattern of pure $\mathrm{Cu}$ as a reference pattern is presented to compare peaks.

Three major peaks corresponding to the FCC phase of $\mathrm{Cu}$ exist in all the patterns. Cubic structure of $\mathrm{Cu}$ can be shown by (111), (200) and (220) planes. Generally, the XRD patterns of MWCNTs consist of three peaks at $26^{\circ}, 43^{\circ}$, and $54^{\circ}$. However, according to the Fig 6, there is not any observable peak for CNTs in these patterns. The absence of the peaks can be explained because the detection limit of the XRD instrument is greater than $5 \mathrm{wt} \%$ [31], and the low crystallinity of carbon [32-33]. Although the nanocomposite samples are more prone to oxidation [24], no copper oxide 
diffraction peak is seen at $36.5^{\circ}$ due to the weakness of XRD analysis to detect a trace of elements [31]. LECO combustion analysis has been used to detect a low level of oxygen element in $\mathrm{Cu}-1 \mathrm{wt}$ \% CNTs nanocomposite produced by DPDS method (Fig. 7). In addition, according to these patterns, no chemical reaction occurred between $\mathrm{Cu}$ and CNT particles over both sintering processes.

As it can be proven from the Fig. 6, the patterns of nanocomposites produced by DPDS method indicate peaks that are broader than that of nanocomposites produced by the conventional sintering method. Refined grains and micro-strains [9] could cause broader peaks in nanocomposites produced by DPDS method (Fig. 6 (b)).

(a)

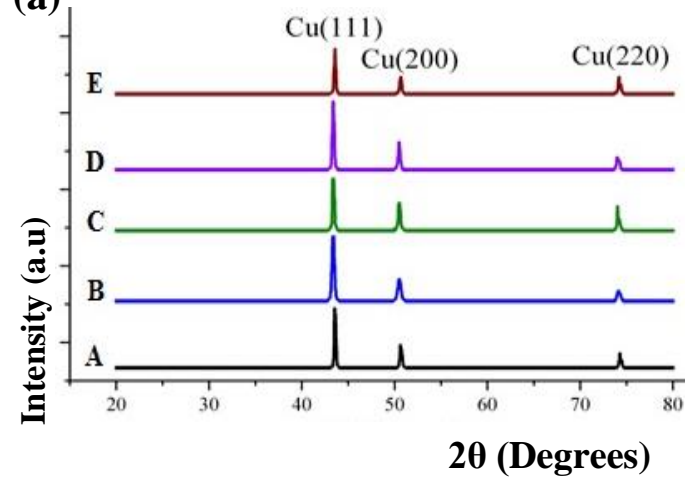

(b)

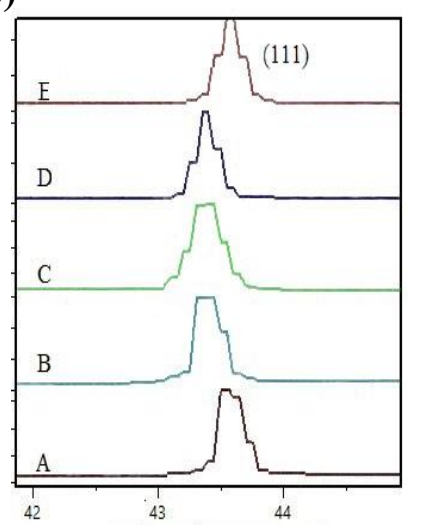

Fig. 6. XRD patterns of A: Cu pure, B: $C u-1$ wt.\% CNTs nanocomposite produced by conventional sintering method, $C: C u-1 \mathrm{wt} . \%$ CNTs nanocomposite produced by DPDS method, D: $C u-1.5$ wt.\% CNTs nanocomposite produced by conventional sintering method, E: Cu-1.5 wt.\% CNTs nanocomposite produced by DPDS method.

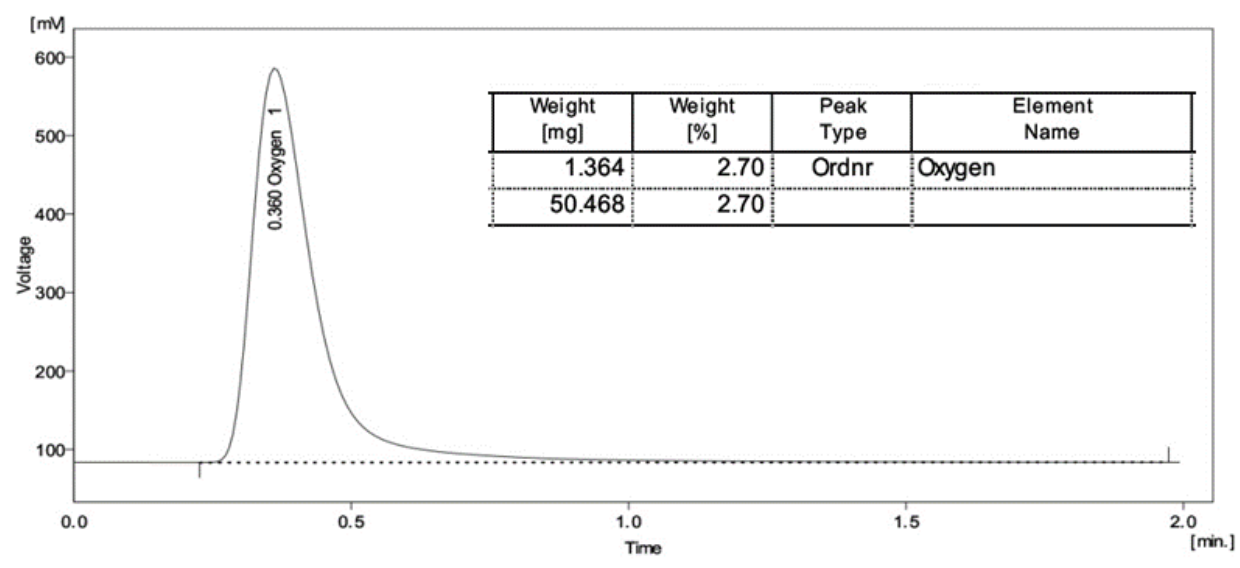

Fig. 7. LECO combustion analysis of the Cu-1 wt.\% CNTs nanocomposite produced by the DPDS method. 


\section{Physical properties}

The relative density of $\mathrm{Cu}$-CNTs nanocomposites fabricated by conventional sintering and DPDS methods are presented in Fig. 8(a). As seen, the measured density of composites was decreased by increasing weight percent of CNTs in both methods.

The sintering mechanism of composites involves diffusion of $\mathrm{Cu}$ atoms at the sintering temperature. It seems that the CNTs are located at the prior particle boundaries. The lowest density in both methods refers to the $1.5 \mathrm{wt} . \%$ CNTs composite that could be due to the lower density of CNTs [8] and the agglomeration of CNTs at the prior particle boundaries. In other words, when the amount of CNTs increases, agglomeration of nanotubes [10] occurs; the CNTs inhibit the diffusion of $\mathrm{Cu}$ into their minor spaces that resulted in agglomeration and formation of the pores during the sintering process. In addition, by increasing the amount of CNTs agglomeration, the number of voids inside the Cu-CNTs nanocomposites samples increases [10]. The agglomeration also prevents extremely effective interfacial bonding between the CNTs and $\mathrm{Cu}[8]$.

As shown in Fig. 8 (a), the samples of DPDS method possess higher density in comparison with the samples of conventional sintering method. The initial pressing of powders results to work hardening of $\mathrm{Cu}$ powders, while pre-sintering causes annealing of $\mathrm{Cu}$ powders. As a result, higher density could be obtained in second pressing and sintering as compared with conventional sintering method. The most considerable feature of the DPDS method which leads to higher density including densification of microstructure and elimination of structural pores is due to the pre-sintering and second step of pressing. In addition, copper which results in outstanding compressibility has a substantial effect on densification of samples [34].

In order to investigate the effect of the second step of pressing in DPDS method, a comparison between sinterability of $\mathrm{Cu}$ samples produced by conventional sintering and DPDS methods has been made, as shown in Fig. 8 (b). Sinterability of the compacts follows by the equation [35]:

$$
\varphi=\frac{\rho_{s}-\rho_{g}}{\rho_{t h}-\rho_{g}}
$$

Where, $\rho_{s}, \rho_{g}$ and $\rho_{t h}$ are the sintered, green and theoretical densities, respectively. As it is observed, sinterability of the samples increased as a result of presintering and second step of pressing in DPDS method. It is evident that second pressing has a significant influence on sinterability of samples produced by DPDS method which led to higher density, as discussed. 
(a)

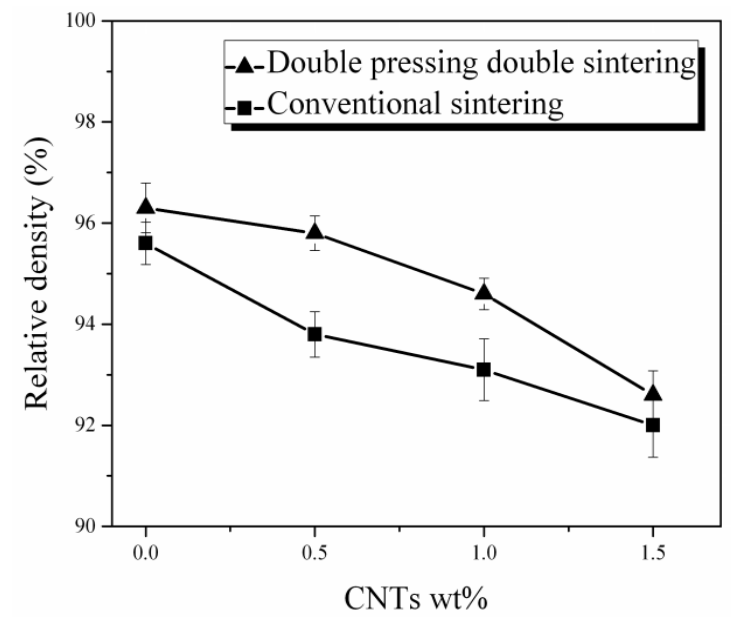

(b)

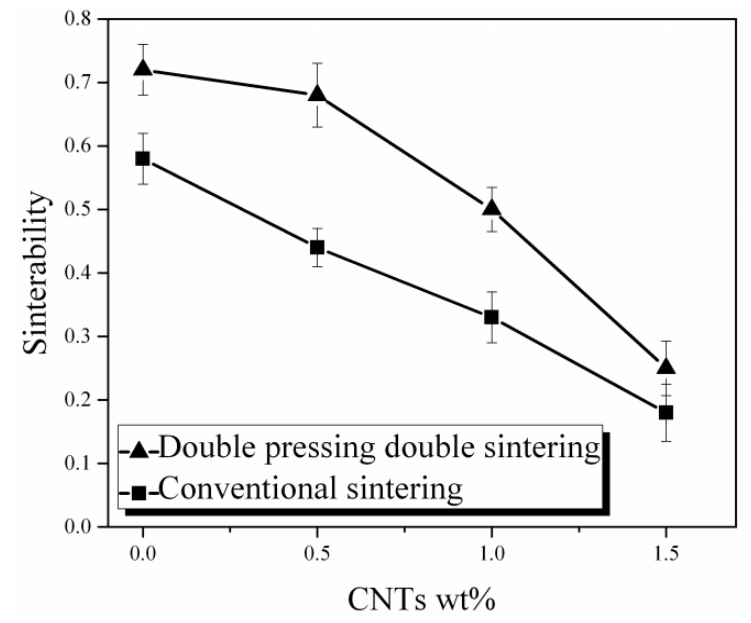

Fig. 8. a) Relative density and b) sinterability of the Cu-CNTs nanocomposites prepared by conventional sintering and DPDS methods as a function of CNTs wt.\%.

Fig. 9. shows the electrical conductivity of $\mathrm{Cu}-\mathrm{CNTs}$ nanocomposites as a function of CNTs wt.\% produced by conventional sintering and DPDS methods. Electrical conductivity is affected by the amount of CNTs and their dispersion, and also sintering method of $\mathrm{Cu}-\mathrm{CNT}$ s nanocomposites. As shown in Fig. 9, there is a decrease in the electrical conductivity values of nanocomposites with increase in the amount of CNTs for both methods. The reduction is due to the presence of some defects, such as voids and interfaces between $\mathrm{Cu}$ matrix and $\mathrm{CNTs}$, which operate as barriers against 
electron mobility and decline the conductivity. The latter might be due to the agglomeration of CNTs at $\mathrm{Cu}$ interfaces, creating a type of boundary which scatters the charge carriers at the interface. It is interesting to note that CNTs as nanoparticles have a major effect on the electrical conductivity. The addition of CNTs which cause a decrease in the grain size by increasing grain boundaries in the microstructure plays a key role in decreasing electrical conductivity through created grain boundaries as sources of electron scattering [36]. Fig. 9 shows the electrical conductivity values of $\mathrm{Cu}-\mathrm{CNT}$ s nanocomposites produced by DPDS method which have a conductivity higher than those of $\mathrm{Cu}-\mathrm{CNT}$ s nanocomposites produced by the conventional sintering method. It can be explained by the decrease of porosity and voids in microstructures of $\mathrm{Cu}-\mathrm{CNT}$ nanocomposite samples produced by DPDS method. Processes of presintering, second pressing and final sintering in DPDS method resulted in lower porosity and voids compared to conventional sintering method.

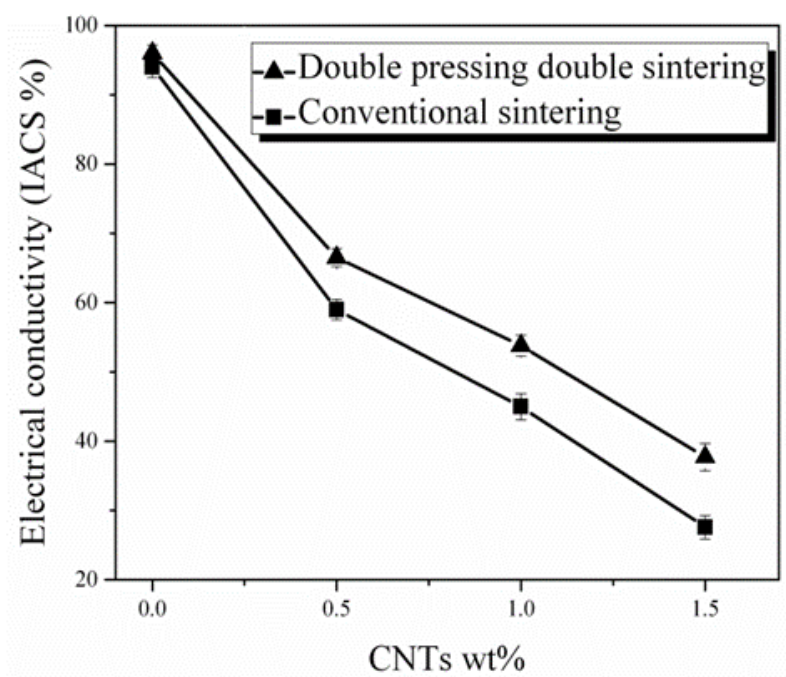

Fig. 9. The electrical conductivity variations of $\mathrm{Cu}$-CNTs nanocomposites with increasing weight percent of CNTs in conventional sintering and DPDS methods.

\section{Mechanical properties}

The hardness and bending strength values of $\mathrm{Cu}-\mathrm{CNT}$ s are higher than $\mathrm{Cu}$ without CNTs in both methods (Fig. 10). This can be explained by the following reasons: First, the movement of dislocations in the matrix is effectively stopped by CNTs as the CNTs are located at the prior particle boundaries, as shown. Second, the matrix of $\mathrm{Cu}-\mathrm{CNT}$ s nanocomposites contains a higher dislocation density because of dislocation generation due to the difference between thermal expansion coefficient of $\mathrm{Cu}$ and $\mathrm{CNT}$. The difference produces thermal mismatch stresses, increasing dislocation density, micro-hardness, and bending strength.

As shown in Fig. 10, the average Vickers micro-hardness and bending strength values increase by increasing the number of CNTs in both methods. Micro-hardness of the $\mathrm{Cu}-1$ wt.\% CNTs nanocomposite exhibits a higher value of hardness than other nanocomposites. For this weight percent in DPDS method, there is an enhancement of about $31.6 \%$ in comparison with conventional sintering method. According to the 
theory of short fiber reinforced composites, as the nanotubes distribute uniformly in the matrix, effectively inhibits matrix deformation and produces a strengthening effect. Fig. 10 shows the bending strength as a function of CNTs wt.\%. It shows that the bending strength increases from $140.50 \mathrm{MPa}$ for nanocomposite containing $1 \mathrm{wt} \% \mathrm{CNTs}$ produced by conventional sintering method to $185.52 \mathrm{Mpa}$ for $\mathrm{Cu}-1 \mathrm{wt} \% \mathrm{CNTs}$ nanocomposite produced by DPDS method; about $32 \%$ increase.

(a)

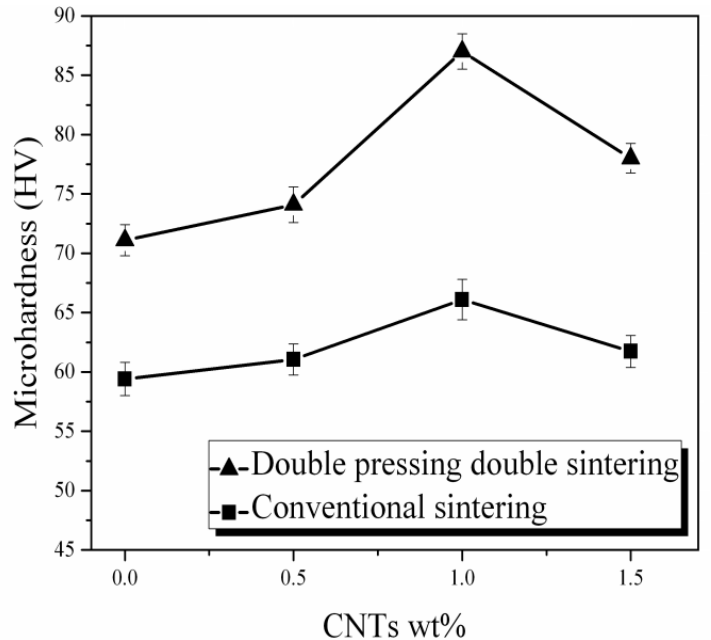

(b)

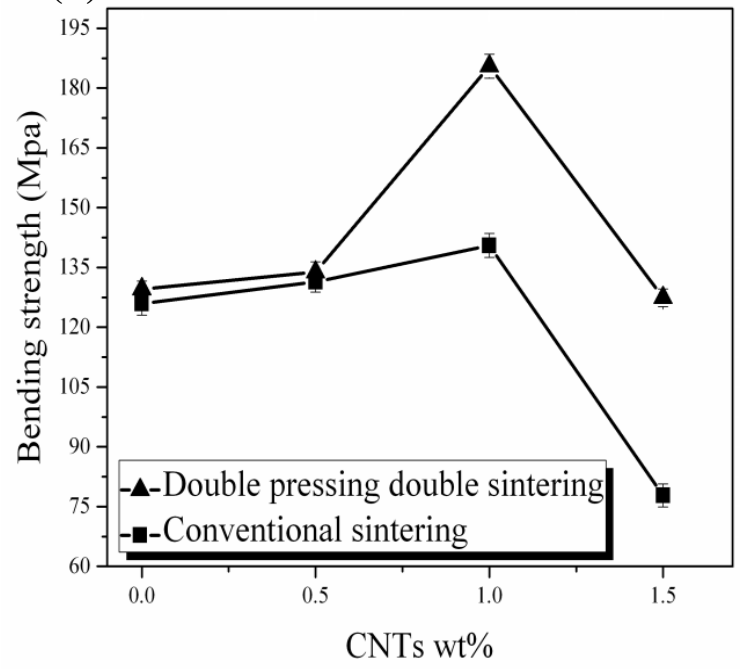

Fig. 10. Comparison of a) micro-hardness and b) bending strength of nanocomposites fabricated by conventional sintering and DPDS methods as a function of CNTs wt.\%. 
However, by increasing the CNTs higher than $1 \mathrm{wt} . \%$, the hardness and bending strength decrease, because of agglomeration of the CNTs, and also the presence of pores, which are main reasons for the decrease of these mechanical properties [37]. In addition, agglomeration of the nanotubes leads to poor interface between nanotubes resulting a weak bonding and failure under the load.

Moreover, it is observed that the average Vickers micro-hardness and bending strength values of samples obtained from DPDS method are higher than nanocomposites produced by the conventional sintering method. The second pressing and sintering process cause grain refinement and deformation strengthening of the matrix, because of which higher Vickers micro-hardness and bending strength values are obtained.

There are several hypotheses for the reinforcing mechanisms explaining the enhanced mechanical properties. To fully understand the strengthening mechanisms that take place in the $\mathrm{Cu}$-based nanocomposites reinforced with nano-fibers (MWCNTs), additional work is required. Nevertheless, we should consider the following hypotheses: (i) inhibition of dislocation motion by MWCNTs, (ii) thermal mismatch between MWCNTs and $\mathrm{Cu}$, (iii) formation of a transition layer between the MWCNTs and the $\mathrm{Cu}$ matrix, (iv) grain refining produced by $\mathrm{MM}$ process, and (v) formation (crystallization) of $\mathrm{Cu}_{2} \mathrm{O}$ [38]. Orowon strengthening, grain, and substructure strengthening, quench hardening resulting from the dislocations generated to accommodate the differential thermal contraction between the reinforcing particles and matrix, and work hardening due to the strain misfit between the elastic reinforcing particles and the particle matrix is also the possible strengthening mechanisms, which may operate simultaneously leading to increased hardness and elastic modulus of the particle-reinforced metal matrix composites [38]. Although improvement in mechanical properties is under influence of aforementioned strengthened mechanisms, inhibition of dislocation motion by CNTs and increasing of dislocation density produced by MM process of powders [36] and thermal mismatch between CNTs and $\mathrm{Cu}$ could be effective mechanisms to improve mechanical properties in this research work. It is noteworthy to mention that other researchers have performed some research to investigate the significant effect of second pressing and sintering on a metal matrix which led to considerable enhancement of mechanical properties [28, 38, 39].

\section{Conclusion}

$\mathrm{Cu}-\mathrm{CNT}$ s nanocomposites were successfully fabricated by DPDS method. The micro-hardness and bending strength increase with increasing amount of CNTs up to 1 wt.\% in DPDS method. The composite with $1 \mathrm{wt} . \%$ CNTs content produced by DPDS process indicates an enhancement of about $31.6 \%$ in micro-hardness, $32 \%$ in bending strength and $19.5 \%$ in electrical conductivity compared to the nanocomposite containing 1 wt.\% CNTs fabricated by a conventional sintering process. It is noteworthy to mention that double pressing double sintering method is an appropriate and newly used method for synthesis of $\mathrm{Cu}-\mathrm{CNTs}$ nanocomposites in comparison with conventional sintering method due to refined grain microstructure and improved properties. 


\section{Acknowledgment}

The authors would like to thank INSF of Iran Contract Number of 94/sad/42699 on $9 / 11 / 2015$ for complete financial support provided for this research work.

\section{References}

[1] X. Wei, H. Rui, L. Jin-Shan, F. Heng-Zhi: Transactions of the Nonferrous Metals Society of China, 21(10) (2011) 2237-41.

[2] P. G. Koppad, H. R. Aniruddha Ram, C. S. Ramesh, K. T. Kashyap, R. G. Koppad: Alloys and Compounds, 580 (2013) 527-532.

[3] A. K. Shukla, N. Nayan, S. V. S. N. Murty, S. C. Sharma, P. Chandran, S. R. Bakshi, K. M. George: Materials Science and Engineering, A 560 (2013) 365-371.

[4] S. Marchisio: PhD Thesis Politecnico di Torino, (2013).

[5] H. T. Bui, B. T. Tran, D. Q. Le, X. T. Than, D. P. Doan, N. M. Phan: Advances in Natural Sciences: Nano-science and Nanotechnology, 2(1) (2011) 015006.

[6] S. Iijima: Nature, 354(6348) (1991) 56-58.

[7] P. V. Trinh, T. B. Trung, N. B. Thang, B. H. Thang, T. X. Tinh, D. D. Phuong, P. N. Minh: Computational Materials Science, 49(4) (2010) S239-S241.

[8] K. Rajkumar, S. Aravindan: Wear, 270(9) (2011) 613-621.

[9] E. J. T. Pialago, C. W. Park: Applied Surface Science, 308 (2014) 63-74.

[10] W. M. Daoush, B. K. Lim, C. B. Mo, D. H. Nam, S. H. Hong: Materials Science and Engineering, A 513 (2009) 247-253.

[11] S. M. Uddin, T. Mahmud, C. Wolf, C. Glanz, I. Kolaric, C. Volkmer, H. Höller, U. Wienecke, S. Roth, H. Fecht: Composites Science and Technology, 70(16) (2010) 2253-2257.

[12] K. Chu, Q. Wu, C. Jia, X. Liang, J. Nie, W. Tian, G. Gai, H. Guo: Composites Science and Technology, 70(2) (2010) 298-304.

[13]Z. Sadeghian, D. Pourjafar, M. Alehoseini: Sci. of Sint, 42 (2010).

[14]G. Chai, Y. Sun, Q. Chen: Micromechanics and Micro-engineering, 18(3) (2008) 035013.

[15]E. Khaleghi, M. Torikachvili, M. A. Meyers, E. A. Olevsky: Materials Letters, 79 (2012) 256-258.

[16] K. Chu, H. Guo, C. Jia, F. Yin, X. Zhang, X. Liang, H. Chen: Nano-scale research letters, 5(5) (2010) 868.

[17]H. Li, A. Misra, Y. Zhu, Z. Horita, C. C. Koch, T. G. Holesinger: Materials Science and Engineering, A 523(1) (2009) 60-64.

[18] G. S. Cho, H. Jang, J. K. Lim, K. H. Choe, H. G. Jeong: In 18TH International conference on composite materials, in Jeju Island, Korea (2011)

[19] S. Dong, J. Zhou, D. Hui, Y. Wang, S. Zhang: Composites Part A: Applied Science and Manufacturing, 68 (2015) 356-364.

[20] A. K. Shukla, N. Nayan, S. V. S. N. Murty, K. Mondal, S. C. Sharma, K. M. George, S. R. Bakshi: Materials characterization, 84 (2013) 58-66.

[21] D. H. Nam, Y. K. Kim, S. I. Cha, S. H. Hong: Carbon 50(13) (2012) 4809-4814. 
[22]P. Jenei, J. Gubicza, E. Y. Yoon, H. S. Kim, J. L. Lábár: Composites Part A: Applied Science and Manufacturing, 51 (2013) 71-79.

[23]V. Koti, R. George: International Conference on Challenges and Opportunities in Mechanical Engineering, (2012) 219-224.

[24] M. Lal, S. K. Singhal, I. Sharma, R. B. Mathur: Applied Nano-science, 3(1) (2013) 29-35.

[25]J. D. B. De Mello, R. Binder, A. N. Klein, I. M. Hutchings: Powder Metallurgy, 44(1) (2001) 53-61.

[26] J. D. B. De Mello, I. M. Hutchings: Wear, 250(1) (2001) 435-448.

[27]D. Milligan, U. Engstrom, J. Lingenfelter, S. Dizdar, I. Nyberg: SAE Technical Paper, 2003-01-0338 (2003).

[28] G. Hammes, R. Schroeder, C. Binder, A. N. Klein, J. D. B. de Mello: Tribology International, 70 (2014) 119-127.

[29] W. B. James, R. J. Causton, J. J. Fulmer: U.S. Patent, 5,080,712 (1992).

[30]R. M. German, Powder metallurgy and particulate materials processing: the processes, materials, products, properties, and applications, 1st ed., Princeton, NJ: Metal powder industries federation, 2005, 528.

[31]W. M. Daoush: Powder Metallurgy and Metal Ceramics, 47(9-10) (2008) 531-537.

[32]Z. W. Xue, L. D. Wang, P. T. Zhao, S. C. Xu, J. L. Qi, W. D. Fei: Materials \& Design, 34 (2012) 298-301.

[33]P. Liu, D. Xu, Z. Li, B. Zhao, E. S. Kong, Y. Zhang: Microelectronic Engineering, 85(10) (2008) 1984-1987.

[34] S. R. Hashemi, M. Ardestani, A. Nemati: Science of Sintering, 48(1) (2016) 71-79.

[35]D. Jeyasimman, K. Sivaprasad, S. Sivasankaran, R. Narayanasamy: Powder Technology, 258 (2014) 189-197.

[36] M, Korać, Z. Kamberović, Z. Anđić, M. Filipovic, In Nanocomposites and Polymers with Analytical Methods, InTech (2011).

[37]C. B. Lin, Z. Chang, Y. H. Tung, Y. Ko: Wear, 270(5) (2011) 382-394.

[38] A. Yarahmadi, M. T. Noghani, M. Rajabi: Materials Research, 31(24) (2016) 38603868.

[39] J. A. Rodriguez, J. M. Gallardo, E. J. Herrera: materials processing technology, 56(1-4) (1996) 254-262.

\section{(c) (i) Creative Commons License}

This work is licensed under a Creative Commons Attribution 4.0 International License. 